\title{
Plasma endocannabinoid alterations in individuals with substance use disorder are dependent on the "mirror effect" of schizophrenia
}

\section{Joëlle Desfossés ${ }^{1}$, Emmanuel Stip ${ }^{2}$, Lahcen Ait Bentaleb ${ }^{2}$, Olivier Lipp ${ }^{1}$, Jean-Pierre Chiasson ${ }^{3}$, Alexandra Furtos ${ }^{4}$, Karine Venne ${ }^{4}$, Edouard Kouassi ${ }^{1,5}$ and Stéphane Potvin ${ }^{1}$ *}

1 Department of Psychiatry, Faculty of Medicine, Fernand-Seguin Research Centre, Université de Montréal, Montréal, QC, Canada

2 Department of Psychiatry, Faculty of Medicine, Centre Hospitalier de I'Université de Montréal, Université de Montréal, Montréal, QC, Canada

${ }^{3}$ Clinique du Nouveau-Départ, Montréal, QC, Canada

${ }^{4}$ Department of Chemistry, University of Montreal, Montréal, OC, Canada

${ }^{5}$ Department of Medicine, Faculty of Medicine, Maisonneuve-Rosemont Hospital Research Center, Université de Montréal, Montréal, QC, Canada

\section{Edited by:}

Marco Diana, University of Sassari,

Italy

\section{Reviewed by:}

Gabriel Rubio, Hospital Universitario 12 de Octubre, Spain

Diana Martinez, Columbia University, USA

\section{*Correspondence:}

Stéphane Potvin, Department of Psychiatry, Faculty of Medicine, Fernand-Seguin Research Centre, Université de Montréal, 7331 Hochelaga, Montreal, OC, Canada H1N 3 V2.

e-mail:stephane.potvin@

umontreal.ca
Schizophrenia is a complex psychiatric disorder strongly associated with substance use disorders. Theoretically, schizophrenia and SUD may share endocannabinoid alterations in the brain reward system. The main endocannabinoids, anandamide, and 2-arachidonoylglycerol, are lipids which bind cannabinoid receptors. Oleoylethanolamide (OEA), a fatty-acid ethanolamide, binds peroxisome proliferator-activated receptors. The endocannabinoid system has been shown to be impaired in schizophrenia, and recently, our group has shown that schizophrenia patients with SUD have elevated peripheral levels of anandamide and OEA that do not normalize after 3-month treatment with quetiapine. Objective For comparative purposes, we aimed to measure endocannabinoids in non-psychosis substance abusers and non-abusing schizophrenia patients. Methods Using liquid chromatography and mass spectrometry, we measured plasma levels of anandamide and OEA in nonpsychosis SUD patients, non-abusing schizophrenia patients, and healthy controls. In an open-label manner, all patients received 12-week treatment with quetiapine. Results Anandamide and OEA were reduced in substance abusers without schizophrenia, relative to healthy controls $(p<0.05)$. Both endocannabinoids were unchanged in non-abusing schizophrenia patients. After quetiapine, anandamide, and OEA levels remained significantly reduced the SUD group $(p<0.05)$. Discussion Taken together with results of our previous study performed in dual-diagnosis patients, our results suggest that peripheral anandamide and OEA levels are impaired in patients with SUD in opposite ways according to the presence or absence of schizophrenia. Endocannabinoid alterations did not change with treatment, suggesting that they are trait markers. Further studies are necessary to understand the role of endocannabinoids in substance abusers with and without schizophrenia and to examine therapeutic implications.

Keywords: schizophrenia, endocannabinoids, anandamide, oleoylethanolamide, substance use disorder, vulnerability marker

\section{INTRODUCTION}

Schizophrenia is a complex disease encompassing $0.87 \%$ of the general population (Perala et al., 2007). Psychiatric symptoms and comorbidities such as substance use disorder (SUD) contribute to the associated disability. The lifetime prevalence of SUD is approximately 40\% in schizophrenia (Regier et al., 1990). It has a negative impact on drug compliance, psychotic relapses, and on prognosis. Patients with schizophrenia are more prone to substance abuse than the general population and $25 \%$ have a lifetime prevalence of cannabis abuse/dependence, the most widely used illicit psychoactive substance worldwide (Jablensky, 2000). Cannabinoid intoxication can provoke cognitive deficits and psychiatric symptoms akin to the cognitive and positive symptoms of schizophrenia (D'Souza et al., 2004). Chronically, cannabis smoking seems to provoke an amotivational syndrome similar to the negative symptoms of the disorder (Nunez and Gurpegui, 2002). Cannabinoid intoxication has therefore become a valid psychosis model, because its effects are representative of the full spectrum of schizophrenia symptoms. The endogenous cannabinoid (ECB) system may help to understand the link between schizophrenia and substance abuse.

The main ECBs, anandamide, and 2-arachidonoylglycerol (2$A G)$, are lipids naturally derived from membrane precursors which bind cannabinoid receptors $\left(\mathrm{CB}_{1}, \mathrm{CB}_{2}\right.$; Ameri, 1999). Although structurally related to anandamide, palmitoylethanolamide (PEA), and oleoylethanolamide (OEA) are two non-cannabinoid natural bioactive fatty-acid ethanolamides (FAEA), as these lipids do not bind cannabinoids receptors, but bind with high affinity to the 
peroxisome-proliferator-activated receptor- alpha (PPAR- $\alpha$; Fu et al., 2003). ECBs are synthesized on request by neurotransmitters and the ECB system is involved in several neuromodulation processes.

Preliminary evidence suggests that the ECB system is disturbed in schizophrenia (Desfossés et al., 2010). Indeed, postmortem human brain studies have shown that $\mathrm{CB}_{1}$ receptor density is elevated in several brain regions involved in the pathophysiology of schizophrenia, such as the prefrontal cortex, the hippocampus, and the basal ganglia (Dean et al., 2001). Similarly, a recent positron emission tomography (PET) study has brought new insights about the link between schizophrenia and $\mathrm{CB}_{1}$ receptors. In vivo, it showed an elevation of $\mathrm{CB}_{1}$ receptor binding in patients with schizophrenia across many brain regions, significantly in the pons, relative to healthy controls (HC; Wong et al., 2010). $\mathrm{CB}_{1}$ receptor functioning may also be altered in schizophrenia in brain regions involved in cognition. Moreover, anandamide levels are increased in the cerebrospinal fluid (CSF) of patients with schizophrenia compared to healthy controls (HC) (Leweke et al., 1999) and to individuals with other psychiatric disorders (Giuffrida et al., 2004). Inconsistently, anandamide levels have also been shown to be elevated in the serum of schizophrenia patients (De Marchi et al., 2003), suggesting that anandamide may play a protective role in psychosis homeostasis.

Theoretically, schizophrenia and SUD may share ECB alterations in the brain reward system. The study of ECB ligands, such as anandamide and OEA, may provide mechanistic explanations for the increased vulnerability to SUD in schizophrenia patients and/or the increased vulnerability to develop psychotic symptoms in individuals with SUD. Studies are therefore needed to explore the role of the ECB system in the pathophysiology of schizophrenia which consider the impact of substance abuse.

A previous study of our group of research examined plasma endocannabinoid in patients with dual-diagnosis schizophrenia (Potvin et al., 2008). Plasma anandamide and OEA levels were elevated at baseline in patients compared to controls and were not modified after 12 weeks of treatment with the second-generation antipsychotic quetiapine. In the present study, we report plasma anandamide and OEA concentrations in substance abusers without schizophrenia and in non-abusing schizophrenia patients assessed in the same clinical conditions and included following the same criteria as the patients with dual-diagnosis. We examined endocannabinoid outcomes in substance abusers without schizophrenia and in non-abusing schizophrenia patients undergoing 12-week treatment with quetiapine. This antipsychotic was chosen because it has previously been shown to improve substance use and psychiatric outcomes in psychosis, dual-diagnosis, and non-psychosis patients (Kampman et al., 2007; Martinotti et al., 2008; Potvin et al., 2008; Rizkallah et al., 2010). Importantly, this is the first study of its kind to trace endocannabinoid outcomes prospectively in these groups. During the trial, we sought to determine whether: (i) baseline plasma anandamide and OEA concentrations were different between patients and controls, (ii) plasma anandamide and OEA levels varied from baseline to endpoint.

\section{MATERIALS AND METHODS PARTICIPANTS}

To complement the data collected previously in dual-diagnosis schizophrenia patients and HC (Potvin et al., 2008), three groups of participants were recruited, namely: (i) non-abusing patients with schizophrenia-spectrum disorders (schizophrenia, schizoaffective disorder, schizophreniform disorder; SCZ group); (ii) nonpsychotic substance abusers in detoxification (SUD group); and (iii) a new group of HC. Psychiatric and SUD diagnoses were by well-trained psychiatrists and physicians, and were all based on DSM-IV criteria. SUD diagnoses were complemented with urine drug screenings. All participants signed a detailed consent form. The study was approved by the local ethics committee.

For all patient groups (SCZ and SUD), exclusion criteria were: (i) patients already on clozapine or quetiapine; (ii) patients hospitalized in a psychiatric unit; (iii) pregnancy; (iv) female subjects of childbearing potential or inadequate contraception; and (v) clinically meaningful unstable, renal, hepatic, cardiovascular, respiratory, cerebro-vascular, or other serious, progressive physical disease. For the SCZ group, patients were excluded if their total score on the Positive and Negative Syndrome Scale (PANSS; Kay et al., 1987) was lower than 65. Importantly, these exclusion criteria are the same as the ones used in our previous study involving dual-diagnosis patients (Potvin et al., 2008). SUD patients were diagnosed with one or more of the following SUD: alcohol $(n=24)$; cannabis $(n=20)$; stimulants $(n=15)$. SCZ patient received one or more first-generation $(n=5)$ or secondgeneration antipsychotics $(n=14)$, four patients were drug-free. For study completers, the mean quetiapine dose was $478.3 \mathrm{mg}$ (272.0) and $150.0 \mathrm{mg}$ (117.7) in the SCZ and SUD groups, respectively. Of note, in the previous study, dual-diagnosis schizophrenia patients used similar psychoactive substances, were taking similar types of antipsychotics and received similar doses of quetiapine (for more information, see Potvin et al., 2008).

\section{CLINICAL ASSESSMENTS}

Psychiatric symptoms were measured using the PANSS and the Calgary Depression Scale for Schizophrenia (CDSS; Addington et al., 1993). Quantities of substances used in the last week were also registered, using the TimeLine Follow-Back (TLFB) procedure (Sobell et al., 1992). Quantities used were noted for all substances. Amount spent on substances was calculated based on the value market in Quebec province (Canada). To complement our evaluation of SUD, urine screenings were performed before and after treatment. SUD severity was also evaluated using the Alcohol Use and the Drug Use Scales (Drake et al., 1990; for more information, see Potvin et al., 2008; Rizkallah et al., 2010).

\section{ANALYSIS OF AEA AND OEA FROM PLASMA}

We collected blood samples $(2 \mathrm{~mL})$ using heparinized tubes. Within $1 \mathrm{~h}$, blood samples were centrifuged ( $3200 \mathrm{rpm}$ for $15 \mathrm{~min}$ ), and plasma $(1 \mathrm{~mL})$ was stored at $-80^{\circ} \mathrm{C}$ in glass vials. Blood samples were collected before and after treatment. All extraction manipulations were done on ice or at $4^{\circ} \mathrm{C}$. Plasma $(500 \mu \mathrm{L})$ was spiked with $1 \mathrm{ng}$ of internal standard AEA-d8. All samples were thoroughly vortexed and centrifuged at $15,000 \mathrm{~g}$ for $5 \mathrm{~min}$. The Solid Phase Extraction was conducted according to the method 
developed by Marczylo et al. (2009) with slight modifications. LCMS-MS analyses were performed on a Surveyor coupled to a TSQ Quantum AM Ultra (ThermoFisher, San Jose, CA, USA) operating in positive electrospray mode. For each analyte, silver adducts were selected for multiple reaction monitoring (MRM). Injections of $5 \mu \mathrm{L}$ were done on a $2.6 \mu \mathrm{m}$ Kinetex C18 $3.0 \times 100 \mathrm{~mm}$ column (Phenomenex, Torrance, CA, USA) and separated using a linear gradient. The eluants consisted of $70 \mu \mathrm{M}$ aqueous silver acetate (solvent A), $70 \mu \mathrm{M}$ silver acetate in $90 \%$ methanol $/ 10 \% \mathrm{H}_{2} \mathrm{O}$ (solvent $\mathrm{B}$ ), and $70 \mu \mathrm{M}$ silver acetate in $90 \%$ acetonitrile $/ 10 \% \mathrm{H}_{2} \mathrm{O}$ (solvent C). The separation started at $30 \% \mathrm{~A}, 20 \% \mathrm{~B}$, and $50 \% \mathrm{C}$ and ended at $0 \% \mathrm{~A}, 20 \% \mathrm{~B}$, and $80 \% \mathrm{C}$ for a total run time of $20 \mathrm{~min}$. The lowest limits of quantitation were $0.10 \mathrm{ng} / \mathrm{mL}$ for AEA and $0.17 \mathrm{ng} / \mathrm{mL}$ for OEA.

\section{STATISTICAL ANALYSES}

Baseline differences between SCZ patients, SUD patients and HC were analyzed using one-way analyses of variance (ANOVA) with group as the independent variable. Dichotomous variables were evaluated using Pearson's chi-square test. Multiple comparisons were performed using the Bonferroni correction. Changes in substance abuse and psychiatric symptoms were analyzed using repeated-measures ANOVA. Last-observation carried forward (LOCF) was used. The level of significance was set at $p<0.05$. Statistical analyses were performed using the Predictive Analytics SoftWare (PASW; version 18).

\section{RESULTS \\ PARTICIPANTS}

Twenty-five SCZ patients were prescribed quetiapine; of these, two were lost-to-follow-up. Thirty-eight SUD patients were recruited, and 33 SUD patients were prescribed quetiapine; of these, two were lost-to-follow-up, two dropped out due to side-effects, and three dropped out due to SUD relapse. Therefore, LOCF analysis was available for 23 and 26 patients in the SCZ and SUD groups, respectively.

\section{SOCIO-DEMOGRAPHIC VARIABLES}

SCZ patients, SUD patients, and HC did not differ in terms of age [HC: 37.1 (12.5); SCZ: 40.3 (12.6); SUD: 37.9 (12.1); $F=0.5$; $p=0.626$ ], sex [HC: 16 males (M), 11 females (F); SCZ: 17M, 8F; SUD: $25 \mathrm{M}, 13 \mathrm{~F} ; \chi^{2}=0.5 ; p=0.785$ ], ethnicity (HC: 26 Caucasian; SCZ: 22 Caucasian; SUD: 34 Caucasian; $\left.\chi^{2}=1.3 ; p=0.517\right)$, and weight [HC: 76.3 (16.2); SCZ: 76.9 (13.2); SUD: 76.5 (18.0); $F=0.01 ; p=0.992]$.

\section{SUD OUTCOMES}

In SUD patients, all substance use outcomes significantly improved during treatment $(p<0.05$; for more information, see Rizkallah et al., 2010).

\section{PSYCHIATRIC SYMPTOMS}

On baseline, SCZ and SUD patients had similar positive symptoms [SCZ: 17.4 (4.4); SUD: 16.2 (5.1); $F=3.2 ; p=0.08$ ]; SCZ patients had more negative symptoms than SUD patients [SCZ: 16.9 (4.7); SUD: 13.6 (4.7); $F=7.2 ; p=0.01$ ]; and SUD patients had more depressive symptoms than SCZ patients [SCZ: $3.6(4.4)$; SUD: 6.8 (4.4); $F=8.4 ; p=0.005$; Zhornitsky et al., 2011]. In SCZ and SUD patients, psychiatric symptoms (positive, negative, and depressive) significantly improved during treatment $(p<0.05$; for more information, see Zhornitsky et al., 2011).

\section{ENDOCANNABINOIDS}

Compared to HC, plasma anandamide, and OEA levels were significantly reduced in SUD patients, but not in SCZ patients (Table 1). Peripheral anandamide and OEA remained reduced in the SUD group after quetiapine treatment (Table 2). Noteworthy, sub-analyses targeting specific psychoactive substances (alcohol, cannabis, or stimulants) revealed that AEA and OEA levels were reduced in the SUD group, compared to HC, irrespective of the substance $(p<0.05)$.

\section{DISCUSSION}

Previously, our group has measured plasma levels of anandamide and OEA in 29 schizophrenia patients with comorbid SUDs (cannabis $>$ alcohol $>$ cocaine), before and after 12-week treatment with quetiapine. We found that peripheral levels of anandamide and OEA were both increased in dual-diagnosis patients, relative to controls. Noteworthy, these elevations were not normalized by quetiapine treatment, despite improvements psychiatric and SUD outcomes (Potvin et al., 2008). In the current study, plasma anandamide levels were reduced in SUD patients, but normal in non-abusing schizophrenia patients, and both anandamide and OEA levels remained reduced in the SUD group after quetiapine treatment. Taken together, the results from both studies (previous and current) highlight a striking opposite phenomenon, namely that peripheral anandamide and OEA levels are elevated in dual-diagnosis schizophrenia while both being reduced in nonpsychosis substance abusers. Given that anandamide and OEA alterations were not normalized during treatment, such results strongly suggest that ECB alterations are trait markers of SUD.

Our results have shown that the involvement of ECBs in SUDs is expressed in opposite ways, according to the presence or absence of a comorbid schizophrenia diagnosis, suggesting a "mirror effect." Such a result must be interpreted cautiously. On one hand, given the role of ECBs in the brain reward system, it is possible that elevations of anandamide and OEA levels constitute risk factors leading to SUDs in individuals with psychosis vulnerability. Alternatively, it is also possible that anandamide and OEA elevations are endogenous markers of psychosis vulnerability in the context of

Table 1 | Anandamide and OEA at baseline according to schizophrenia or substance use disorder compared to healthy controls.

\begin{tabular}{llllll}
\hline Variable & HC $(\boldsymbol{n}=\mathbf{2 7})$ & SCZ patients $(\boldsymbol{n}=\mathbf{2 5})$ & SUD patients $(\boldsymbol{n}=\mathbf{3 8})$ & Statistics & Multiple comparison* \\
\hline Anandamide $(\mathrm{ng} / \mathrm{mL})$ & $1.1(0.4)$ & $1.1(0.2)^{* *}$ & $0.7(0.2)$ & $F=24.3 ; p=0.0001$ & $\mathrm{SUD}<\mathrm{HC}$ and SCZ \\
OEA $(\mathrm{ng} / \mathrm{mL})$ & $1.6(0.7)$ & $1.3(0.4)^{* *}$ & $1.0(0.5)$ & $F=11.2 ; p=0.0001$ & $\mathrm{SUD}<\mathrm{HC}$
\end{tabular}

HC, healthy controls; OEA, oleoylethanolamide; SCZ, schizophrenia; SUD, substance use disorders; *After Bonferroni correction; ${ }^{*} n=21$, missing data. 
Table 2 | Changes in plasma endocannabinoid levels during quetiapine treatment.

\begin{tabular}{llll}
\hline Variable & Baseline & LOCF data & Statistics \\
\hline Non-abusing schizophrenia patients $(n=15)^{*}$ & \\
Anandamide $(\mathrm{ng} / \mathrm{mL})$ & $1.1(0.3)$ & $1.0(0.3)$ & $F=0.7 ; p=0.415$ \\
Oleoylethanolamide $(\mathrm{ng} / \mathrm{mL})$ & $1.3(0.4)$ & $1.3(0.3)$ & $F=0.2 ; p=0.635$ \\
Non-psychosis patients with substance use disorders & $(n=24)$ \\
Anandamide $(\mathrm{ng} / \mathrm{mL})$ & $0.7(0.2)$ & $0.7(0.3)$ & $F=0.3 ; p=0.599$ \\
Oleoylethanolamide $(\mathrm{ng} / \mathrm{mL})$ & $1.0(0.5)$ & $1.1(0.6)$ & $F=0.5 ; p=0.508$
\end{tabular}

LOCF, last-observation-carried-forward; * missing data.

substance abuse, more precisely cannabis abuse. Consistently with this latter interpretation, it has been shown that cannabis smoking can produce psychotomimetic effects, and that it moderately increases the risk for psychotic symptoms (Arseneault et al., 2004).

To explain the striking "mirror effect" reported here, one potential explanation may be related to the fact that $\triangle 9$-THC, the main psychoactive agent of cannabis, is a partial agonist at $\mathrm{CB}_{1}$ receptors (Pertwee, 2005), and may therefore produce opposing effects on anandamide and OEA based on a priori psychosis vulnerability. Alternatively, it may produce different psychiatric effects based on the individual's basal ECB tone. To explain this "mirror effect," it may also be relevant to consider the balance between dopamine and ECBs in psychosis homeostasis. Using PET, various studies have shown that amphetamine-induced dopamine release is increased in schizophrenia, mostly in the acute phase of illness (Laruelle, 1998; Guillin et al., 2007). On the opposite, the chronic use of psychoactive substances has been shown to downregulate striatal dopaminergic neurotransmission (Volkow et al., 1993, 1996, 2001; Hietala et al., 1994; Wang et al., 1997; Ginovart et al., 1999; Martinez et al., 2004; Lee et al., 2009). Given that anandamide has been shown to inhibit dopamine release in the striatum, as a retrograde messenger (Giuffrida et al., 1999), and that OEA inhibits drug-induced dopamine elevations in the reward system via PPAR- $\alpha$ (Melis et al., 2008), one may hypothesize that the inverted endocannabinoid alterations in dual-diagnosis patients and SUD patients are the results of complex interactions with dopamine. Against this view, however, it is important to mention that the dopaminergic dysfunctions associated with both schizophrenia and substance abuse are mostly transient (Laruelle, 1998; Volkow et al., 2001), whereas the endocannabinoid alterations reported here and in our previous study are persistent in time (Potvin et al., 2008).

One of the research implications of our results is that longitudinal studies would be needed in adolescent substance users, before they develop schizophrenia or SUD, to understand the involvement of ECBs in SUD - with a particular attention to specific substances, such as alcohol, cannabis, and stimulants. Our results may also have future implications for the pharmacological treatment of SUDs, as they suggest that $\mathrm{CB}_{1}$ or PPARs agonists would be required in substance abusers, whereas $\mathrm{CB}_{1}$ or PPAR antagonists would be required in dual-diagnosis schizophrenia patients. Although $\mathrm{CB}_{1}$ antagonists have shown promise in pre-clinical models of addiction to various substances (Economidou et al.,
2006; Femenia et al., 2010; Yu et al., 2011), and PPAR- $\gamma$ agonists have been shown to reduce alcohol drinking in rodents (Stopponi et al., 2011), the clinical efficacy of $\mathrm{CB}_{1}$ antagonists for SUD remains to be proven (Cahill and Ussher, 2011) and PPAR agonists have not been tested thus far in humans. The adequate pharmacological modulation of ECB tone could also provide therapeutic targets. One of them is fatty-acid amide hydrolase (FAAH), the enzyme responsible for the degradation of anandamide and OEA, which offers a more selective way to alter ECB activity. FAAH inhibitors seem to be potent modulators of motivation and goaldirected behaviors associated with SUD (such as cocaine) without reducing consumption in rat models (Adamczyk et al., 2009). However, FAAH inhibitors have not been tested thus far for the treatment of alcohol or drug addiction in humans.

Our study has three main limitations. First, our study was limited by the inclusion of various psychoactive substances, making the attribution of our results to specific substances difficult. Another limitation of our study is the inclusion in the non-abusing schizophrenia group having a small number of patients. The lack of difference in ECB levels between non-abusing schizophrenia patients and controls could therefore be explained by a type-II error. Finally, we measured peripheral, not central, levels of anandamide, and OEA, and this may have influenced our results. For instance, the absence of difference in plasma anandamide and OEA between non-abusing patients with schizophrenia-spectrum disorders and controls might be explained by various peripheral influences, especially since ECBs are involved in various systems (Hohmann and Suplita, 2006; Pacher et al., 2006; Matias and Di Marzo, 2007; Hiley, 2009). Moreover, the absence of ECB alterations in the schizophrenia group does not preclude central ECB disturbances. Thus far, two studies have shown that anandamide levels are elevated in the CSF of schizophrenia patients (Leweke et al., 1999; Giuffrida et al., 2004) and another one showed that CSF anandamide levels are also elevated in the prodromal phase of psychosis (Koethe et al., 2009). Importantly, CSF OEA levels were not altered in these three studies. As for the peripheral measurement of ECBs in schizophrenia, De Marchi et al. (2003) showed that blood anandamide levels were elevated in small group $(n=12)$ of schizophrenia patients, during the acute phase of illness. In contrast, the serum levels of both anandamide and OEA were shown to be unaltered in schizophrenia (Giuffrida et al., 2004) as well as in the prodromal phase of psychosis (Koethe et al., 2009).

\section{CONCLUSION}

Our study has highlighted a "mirror effect" of comorbid schizophrenia on peripheral ECB alterations in SUDs. Given the lack of changes during treatment in ECB levels, our results further suggest that ECB alterations in SUD are trait-, not state-, dependent. Longitudinal studies are required to investigate the biological reasons for the inverted pattern of ECB alterations in substance abusers with and without schizophrenia. The precise role of specific psychoactive substances on our results will also need to be determined. Research in this field could significantly help elucidate the neurobiological dysfunctions underlying the schizophrenia-substance abuse comorbidity, and it may also open new therapeutic perspectives in the future. 


\section{ACKNOWLEDGMENTS}

This study was funded by a Catalyst grant from the Canadian Institute of Health Research and an academic partnership between the Louis-H Lafontaine Foundation and AstraZeneca Pharmaceuticals. Joelle Desfossés is holder of a Frederick Banting and

\section{REFERENCES}

Adamczyk, P., McCreary, A. C., Przegalinski, E., Mierzejewski, P., Bienkowski, P., and Filip, M. (2009). The effects of fatty acid amide hydrolase inhibitors on maintenance of cocaine and food self-administration and on reinstatement of cocaine-seeking and food-taking behavior in rats. $J$. Physiol. Pharmacol. 60, 119-125.

Addington, D., Addington, J., and Maticka-Tyndale, E. (1993). Assessing depression in schizophrenia: the Calgary Depression Scale. Br. J. Psychiatry Suppl. 22, 39-44.

Ameri, A. (1999). The effects of cannabinoids on the brain. Prog. Neurobiol. 58, 315-348.

Arseneault, L., Cannon, M., Witton, J., and Murray, R. M. (2004). Causal association between cannabis and psychosis: examination of the evidence. Br. J. Psychiatry 184, 110-117.

Cahill, K., and Ussher, M. H. (2011). Cannabinoid type 1 receptor antagonists for smoking cessation. Cochrane Database Syst. Rev. 16, CD005353.

De Marchi, N., De Petrocellis, L., Orlando, P., Daniele, F., Fezza, F., and Di Marzo, V. (2003). Endocannabinoid signalling in the blood of patients with schizophrenia. Lipids Health Dis. 19, 2-5.

Dean, B., Sundram, S., Bradbury, R., Scarr, E., and Copolov, D. (2001). Studies on [3H]CP-55940 binding in the human central nervous system: regional specific changes in density of cannabinoid-1 receptors associated with schizophrenia and cannabis use. Neuroscience 103, 9-15.

Desfossés, J., Stip, E., Bentaleb, L. A., and Potvin, S. (2010). Endocannabinoids and schizophrenia. Pharmaceuticals 3, 3101-3126.

Drake, R. E., Osher, F. C., Noordsy, D. L., Hurlbut, S. C., Teague, G. B., and Beaudett, M. S. (1990). Diagnosis of alcohol use disorders in schizophrenia. Schizophr. Bull. 16, 57-67.

D'Souza, D. C., Perry, E., MacDougall, L., Ammerman, Y., Cooper, T., Wu, Y. T., Braley, G., Gueorguieva, R., and Krystal, J. H. (2004). The psychotomimetic effects of intravenous delta-9tetrahydrocannabinol in healthy individuals: implications for psychosis. Neuropsychopharmacology 29, 1558-1572.

Economidou, D., Mattioli, L., Cifani, C., Perfumi, M., Massi, M., Cuomo, V., Trabace, L., and Ciccocioppo, R. (2006). Effect of the cannabinoid CB1 receptor antagonist SR-141716A on ethanol self-administration and ethanol-seeking behaviour in rats. Psychopharmacology (Berl.) 183 394-403.

Femenia, T., Garcia-Gutierrez, M. S. and Manzanares, J. (2010). CB1 receptor blockade decreases ethanol intake and associated neurochemical changes in fawn-hooded rats. Alcohol. Clin. Exp. Res. 34, 131-141.

Fu, J., Gaetani, S., Oveisi, F., Lo Verme, J., Serrano, A., Rodriguez De Fonseca, F., Rosengarth, A., Luecke, H., Di Giacomo, B., Tarzia, G., and Piomelli, D. (2003). Oleoylethanolamide regulates feeding and body weight through activation of the nuclear receptor PPAR-alpha. Nature 425, 90-93.

Ginovart, N., Farde, L., Halldin, C., and Swahn, C. G. (1999). Changes in striatal D2-receptor density following chronic treatment with amphetamine as assessed with PET in nonhuman primates. Synapse 31, 154-162.

Giuffrida, A., Leweke, F. M., Gerth, C. W., Schreiber, D., Koethe, D., Faulhaber, J., Klosterkotter, J., and Piomelli, D. (2004). Cerebrospinal anandamide levels are elevated in acute schizophrenia and are inversely correlated with psychotic symptoms. Neuropsychopharmacology 29, 2108-2114.

Giuffrida, A., Parsons, L. H., Kerr, T. M., Rodriguez de Fonseca, F., Navarro, M., and Piomelli, D. (1999). Dopamine activation of endogenous cannabinoid signaling in dorsal striatum. Nat. Neurosci. 2, 358-363.

Guillin, O., Abi-Dargham, A., and Laruelle, M. (2007). Neurobiology of dopamine in schizophrenia. Int. Rev. Neurobiol. 78, 1-39.

Hietala, J., Syvalahti, E., Vuorio, K., Nagren, K., Lehikoinen, P., Ruotsalainen, U., Rakkolainen, V., Lehtinen, V., and Wegelius, U. (1994). Striatal D2 dopamine receptor characteristics in neuroleptic-naive schizophrenic patients studied with positron

Charles Best Canada Graduate Scholarships-Master's Award from the Canadian Institutes of Health Research. Stéphane Potvin is holder of a Junior 1 salary award from the Fonds de la Recherche en Santé du Québec. Emmanuel Stip is holder of the Eli Lilly Chair of Schizophrenia from the University of Montreal.

emission tomography. Arch. Gen. Psychiatry 51, 116-123.

Hiley, C. R. (2009). Endocannabinoids and the heart. J. Cardiovasc. Pharmacol. 53, 267-276.

Hohmann, A. G., and Suplita, R. L. (2006). Endocannabinoid mechanisms of pain modulation. AAPS J. 8, 693-708.

Jablensky, A. (2000). Epidemiology of schizophrenia: the global burden of disease and disability. Eur. Arch. Psychiatry Clin. Neurosci. 250, 274-285.

Kampman, K. M., Pettinati, H. M. Lynch, K. G., Whittingham, T., Macfadden, W., Dackis, C., Tirado, C., Oslin, D. W., Sparkman, T., and O'Brien, C. P. (2007). A doubleblind, placebo-controlled pilot trial of quetiapine for the treatment of Type A and Type B alcoholism. J. Clin. Psychopharmacol. 27, 344-351.

Kay, S. R., Fiszbein, A., and Opler, L. A. (1987). The positive and negative syndrome scale (PANSS) for schizophrenia. Schizophr. Bull. 13, 261-276.

Koethe, D., Giuffrida, A., Schreiber, D., Hellmich, M., Schultze-Lutter, F., Ruhrmann, S., Klosterkotter, J., Piomelli, D., and Leweke, F. M. (2009). Anandamide elevation in cerebrospinal fluid in initial prodromal states of psychosis. $\mathrm{Br}$. J. Psychiatry 194, 371-372.

Laruelle, M. (1998). Imaging dopamine transmission in schizophrenia. A review and meta-analysis. Q. J. Nucl. Med. 42, 211-221.

Lee, B., London, E. D., Poldrack, R. A., Farahi, J., Nacca, A., Monterosso, J. R., Mumford, J. A., Bokarius, A. V., Dahlbom, M., Mukherjee, J., Bilder, R. M., Brody, A. L., and Mandelkern, M. A. (2009). Striatal dopamine $\mathrm{d} 2 / \mathrm{d} 3$ receptor availability is reduced in methamphetamine dependence and is linked to impulsivity. J. Neurosci. 29, 14734-14740.

Leweke, F. M., Giuffrida, A., Wurster U., Emrich, H. M., and Piomelli, D. (1999). Elevated endogenous cannabinoids in schizophrenia. Neuroreport 10, 1665-1669.

Marczylo, T. H., Lam, P. M., Nallendran, V., Taylor, A. H., and Konje, J. C. (2009). A solid-phase method for the extraction and measurement of anandamide from multiple human biomatrices. Anal. Biochem. 384, 106-113
Martinez, D., Broft, A., Foltin, R. W., Slifstein, M., Hwang, D. R., Huang, Y., Perez, A., Frankle, W. G., Cooper, T., Kleber, H. D., Fischman, M. W., and Laruelle, M. (2004). Cocaine dependence and D2 receptor availability in the functional subdivisions of the striatum: relationship with cocaineseeking behavior. Neuropsychopharmacology 29, 1190-1202.

Martinotti, G., Andreoli, S., Di Nicola, M., Di Giannantonio, M., Sarchiapone, M., and Janiri, L. (2008) Quetiapine decreases alcohol consumption, craving, and psychiatric symptoms in dually diagnosed alcoholics. Hum. Psychopharmacol. 23, 417-424.

Matias, I., and Di Marzo, V. (2007). Endocannabinoids and the control of energy balance. Trends Endocrinol. Metab. 18, 27-37.

Melis, M., Pillolla, G., Luchicchi, A., Muntoni, A. L., Yasar, S., Goldberg, S. R., and Pistis, M. (2008). Endogenous fatty acid ethanolamides suppress nicotine-induced activation of mesolimbic dopamine neurons through nuclear receptors. J. $\mathrm{Neu}$ rosci. 28, 13985-13994.

Nunez, L. A., and Gurpegui, M. (2002). Cannabis-induced psychosis: a cross-sectional comparison with acute schizophrenia. Acta Psychiatr. Scand. 105, 173-178.

Pacher, P., Batkai, S., and Kunos, G. (2006). The endocannabinoid system as an emerging target of pharmacotherapy. Pharmacol. Rev. 58, 389-462.

Perala, J., Suvisaari, J., Saarni, S. I., Kuoppasalmi, K., Isometsa, E., Pirkola, S., Partonen, T., Tuulio-Henriksson, A., Hintikka, J., Kieseppa, T., Harkanen, T., Koskinen, S., and Lonnqvist, J. (2007). Lifetime prevalence of psychotic and bipolar I disorders in a general population. Arch. Gen. Psychiatry 64, 19-28.

Pertwee, R. G. (2005). Pharmacological actions of cannabinoids. Handb. Exp. Pharmacol. 168, 1-51.

Potvin, S., Kouassi, E., Lipp, O., Bouchard, R. H., Roy, M. A., Demers, M. F., Gendron, A., Astarita, G., Piomelli, D., and Stip, E. (2008). Endogenous cannabinoids in patients with schizophrenia and substance use disorder during quetiapine therapy. J. Psychopharmacol. (Oxford) 22, 262-269. 
Regier, D. A., Farmer, M. E., Rae, D. S., Locke, B. Z., Keith, S. J., Judd, L. L., and Goodwin, F. K. (1990). Comorbidity of mental disorders with alcohol and other drug abuse. Results from the Epidemiologic Catchment Area (ECA) Study. JAMA 264, 2511-2518.

Rizkallah, E., Stip, E., Zhornitsky, S., Pampoulova, T., Gendron, A., Rompre, P. P., Chiasson, J. P., and Potvin, S. (2010). Clinical evolution of substance use disorder patients during treatment with quetiapine: a 12-week, open-label, naturalistic trial. Expert Opin. Pharmacother. 11, 2947-2951.

Sobell, L. C., Toneatto, T., Sobell, M. B., Leo, G. I., and Johnson, L. (1992). Alcohol abusers' perceptions of the accuracy of their selfreports of drinking: implications for treatment. Addict. Behav. 17, 507-511.

Stopponi, S., Somaini, L., Cippitelli, A., Cannella, N., Braconi, S., Kallupi, M., Ruggeri, B., Heilig, M., Demopulos, G., Gaitanaris, G., Massi, M., and Ciccocioppo, R. (2011). Activation of nuclear PPARgamma receptors by the antidiabetic agent pioglitazone suppresses alcohol drinking and relapse to alcohol seeking. Biol. Psychiatry 69, 642-649.

Volkow, N. D., Chang, L., Wang, G. J., Fowler, J. S., Ding, Y. S., Sedler, M., Logan, J., Franceschi, D., Gatley, J., Hitzemann, R., Gifford, A., Wong, C., and Pappas, N. (2001). Low level of brain dopamine D2 receptors in methamphetamine abusers: association with metabolism in the orbitofrontal cortex. Am. J. Psychiatry 158, 2015-2021.

Volkow, N. D., Fowler, J. S., Wang, G. J., Hitzemann, R., Logan, J., Schlyer, D. J., Dewey, S. L., and Wolf, A. P. (1993). Decreased dopamine D2 receptor availability is associated with reduced frontal metabolism in cocaine abusers. Synapse 14, 169-177.

Volkow, N. D., Wang, G. J., Fowler, J. S., Logan, J., Hitzemann, R., Ding, Y. S., Pappas, N., Shea, C., and Piscani, K. (1996). Decreases in dopamine receptors but not in dopamine transporters in alcoholics. Alcohol. Clin. Exp. Res. 20, 1594-1598.

Wang, G. J., Volkow, N. D., Fowler, J. S., Logan, J., Abumrad, N. N., Hitzemann, R. J., Pappas, N. S., and Pascani, K. (1997). Dopamine D2 receptor availability in opiate-dependent subjects before and after naloxoneprecipitated withdrawal. Neuropsychopharmacology 16, 174-182.

Wong, D. F., Kuwabara, H., Horti, A. G., Raymont, V., Brasic, J., Guevara, M., Ye, W., Dannals, R. F., Ravert, H. T., Nandi, A., Rahmim, A., Ming, J. E., Grachev, I., Roy, C., and Cascella, N. (2010). Quantification of cerebral cannabinoid receptors subtype 1 (CB1) in healthy subjects and schizophrenia by the novel PET radioligand [11C]OMAR. Neuroimage 52, 1505-1513.

Yu, L. L., Zhou, S. J., Wang, X. Y., Liu, J. F., Xue, Y. X., Jiang, W., and Lu, L. (2011). Effects of cannabinoid $\mathrm{CB}$ receptor antagonist rimonabant on acquisition and reinstatement of psychostimulant reward memory in mice. Behav. Brain Res. 217 111-116.

Zhornitsky, S., Stip, E., Desfosses, J., Pampoulova, T., Rizkallah, E., Rompre, P. P., Bentaleb, L. A., Lipp, O., Chiasson, J. P., Gendron, A., and Potvin, S. (2011). Evolution of substance use, neurological and psychiatric symptoms in schizophrenia and substance use disorder patients: a 12-week, pilot, case-control trial with quetiapine. Front. Psychiatry 2:22. doi:10.3389/fpsyt.2011.00022
Conflict of Interest Statement: The authors declare that the research was conducted in the absence of any commercial or financial relationships that could be construed as a potential conflict of interest.

Received: 23 July 2012; accepted: 06 September 2012; published online: 25 September 2012

Citation: Desfossés J, Stip E, Bentaleb $L A$, Lipp O, Chiasson J-P, Furtos A, Venne K, Kouassi E and Potvin S (2012) Plasma endocannabinoid alterations in individuals with substance use disorder are dependent on the "mirror effect" of schizophrenia. Front. Psychiatry 3:85. doi: 10.3389/fpsyt.2012.00085

This article was submitted to Frontiers in Addictive Disorders and Behavioral Dyscontrol, a specialty of Frontiers in Psychiatry.

Copyright (c) 2012 Desfossés, Stip, Bentaleb, Lipp, Chiasson, Furtos, Venne, Kouassi and Potvin. This is an openaccess article distributed under the terms of the Creative Commons Attribution License, which permits use, distribution and reproduction in other forums, provided the original authors and source are credited and subject to any copyright notices concerning any third-party graphics etc. 